\title{
Effective Field Approach to Phase Transitions and Some Applications to \\ Ferroelectrics (2nd Edition)
}




\section{World Scientific Lecture Notes in Physics}

\section{Published}

Vol. 55: Lectures in Particle Physics

$D$ Green

Vol. 56: Chaos and Gauge Field Theory

TS Biro, et al.

Vol. 57: Foundations of Quantum Chromodynamics (2nd ed.): An Introduction to Perturbative Methods in Gauge Theories TMuta

Vol. 58: Concepts in Solids, Lectures on the Theory of Solids P. W. Anderson and H. Bunke

Vol. 59: Lattice Gauge Theories: An Introduction (2nd ed.) HJ Rothe

Vol. 60: Massive Neutrinos in Physics and Astrophysics (2nd ed.) R N Mohapatra and $P$ B Pal

Vol. 61: Modern Differential Geometry for Physicists (2nd ed.) $C J$ Isham

Vol. 62: ITEP Lectures on Particle Physics and Field Theory (In 2 Volumes) $M A$ Shifman

Vol. 64: Fluctuations and Localization in Mesoscopic Electron Systems $M$ Janssen

Vol. 65: Universal Fluctuations: The Phenomenology of Hadronic Matter $R$ Botet and M Ploszajczak

Vol. 66: Microcanonical Thermodynamics: Phase Transitions in "Small" Systems DHE Gross

Vol. 67: Quantum Scaling in Many-Body Systems $M$ A Continentino

Vol. 69: Deparametrization and Path Integral Quantization of Cosmological Models C Simeone

Vol. 70: Noise Sustained Patterns: Fluctuations \& Nonlinearities Markus Loecher

Vol. 71: The QCD Vacuum, Hadrons and Superdense Matter (2nd ed.) Edward V Shuryak

Vol. 72: Massive Neutrinos in Physics and Astrophysics (3rd ed.) $R$ Mohapatra and P B Pal

Vol. 73: The Elementary Process of Bremsstrahlung W Nakel and E Haug

Vol. 74: Lattice Gauge Theories: An Introduction (3rd ed.) HJ Rothe 


\section{Effective Field Approach to Phase Transitions and Some Applications to Ferroelectrics (2nd Edition)}

\section{Julio A Gonzalo}

Universidad Automa de Madrid, Spain 
Published by

World Scientific Publishing Co. Pte. Ltd.

5 Toh Tuck Link, Singapore 596224

USA office: 27 Warren Street, Suite 401-402, Hackensack, NJ 07601

UK office: 57 Shelton Street, Covent Garden, London WC2H 9HE

\section{British Library Cataloguing-in-Publication Data}

A catalogue record for this book is available from the British Library.

\section{EFFECTIVE FIELD APPROACH TO PHASE TRANSITIONS AND SOME APPLICATIONS TO FERROELECTRICS (2nd Edition) \\ World Scientific Lecture Notes in Physics - Vol. 76}

Copyright $\odot 2006$ by World Scientific Publishing Co. Pte. Ltd.

All rights reserved. This book, or parts thereof, may not be reproduced in any form or by any means, electronic or mechanical, including photocopying, recording or any information storage and retrieval system now known or to be invented, without written permission from the Publisher.

For photocopying of materiat in this volume, please pay a copying fee through the Copyright Clearance Center, Inc., 222 Rosewood Drive, Danvers, MA 01923, USA. In this case permission to photocopy is not required from the publisher.

ISBN 981-256-875-1 
To the Virgin Mary, Queen of all things created by God, including beautiful phase transitions.

To my parents 
This page is intentionally left blank

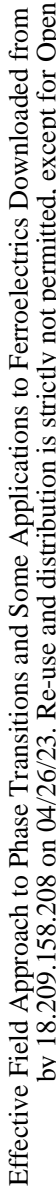




\section{Preface}

The effective field approach to a phase transition, used by Pierre Weiss at the beginning of this century to describe theoretically ferromagnetic transitions in iron, nickel, and cobalt, is the second oldest (surpassed in this respect only by Van der Waals theory of liquid-vapor transitions) and certainly the simplest approach to investigate cooperative phenomena of this kind. Early in the effort to describe satisfactorily the rich variety of physical phenomena accompanying a phase transition, it was realized that the role of fluctuations, introduced by Einstein in 1905 (the same year in which he introduced special relativity and the first successful explanation of the photoelectric effect), was crucial to investigate the subtleties of the behavior of systems undergoing phase changes at temperatures very close to the transition temperature. Of course, the concept of effective field, being an average or mean field, leaves out completely thermodynamic fluctuations. Nevertheless, the effective field approach gives in most cases a good qualitative description of the cooperative phenomena, and in some cases, ferroelectric transitions being an outstanding example, it even gives a fairly good quantitative description. It took some time for prominent theorists to realize that deviations of "classical" (effective field) behavior in ferroelectrics and dipolar ferromagnets should show up in the form of logarithmic corrections, which are very hard to detect experimentally.

This work, which could as well be entitled "Pedestrian approach to Phase Transitions," obviously does not aim at a comprehensive discussion of the effective field approach to phase transitions in general and less so at a discussion that goes deeply beyond this approach to such a broad and active field of contemporary research. It attempts at a simple presentation of the approach, at a very elementary level in most cases, to a number of interesting phase transitions, mostly solid-state transitions, with special attention, 
in the second half of the book, to some work in ferroelectric systems inflecting, unavoidably, the research interest of the author. This material formed the basis for a short graduate course on "Phase Transitions" imparted by the author at the Universidad Autonoma de Madrid, in 1989.

I would like to thank Professor J. Palacios and Professor S. Velayos, former teachers of mine at the University of Madrid, who introduced me to this field; Drs. B.C. Frazer, K. Okada, M. Ray, and G. Shirane, from whom I learned much on ferroelectrics and phase transitions at Brookhaven National Laboratory and at Puerto Rico Nuclear Center; I. Lefkowitz and K.A. Müller to whom I am also indebted; and many of my former graduate students from whom I have also learned a good deal.

Madrid, January 15, 1990

Julio A. Gonzalo 


\title{
Preface to the Second Edition
}

\begin{abstract}
This second edition of Effective Field Approach to Phase Transitions includes additional sections, Parts III-IV, in which additional papers involving the effecitve field approach to Ferroelectric Transitions published in the period 1991-2005 are included.

It is for me a pleasure to give proper credit to the various main authors of these papers: to my younger Spanish colleagues R. Ramirez, G. Lifante, M. de la Pascua, B. Noheda, T. Iglesias, J.R. Fernadez del Castillo, N. Duan, C. Arago, M.I. Marqués, and J. García, some of them at UAM or other Universities in Madrid; and to my long time friends and colleagues from abroad, including G. Shirane (BNL, recently deceased), D. Cox (BNL), C.W. Garland (MIT), J.O. Tocho (La Plata), W. Windsch (Leipzig), M. Koralewski (Poznan), Y.L. Wuag (Shanghai), B. Mroz (Poznan), L. Cross (Penn State), R. Guo (Penn State), and C.L. Wang (Sandong).
\end{abstract}

Madrid, November 15, 2005

Julio A. Gonzalo 
This page is intentionally left blank

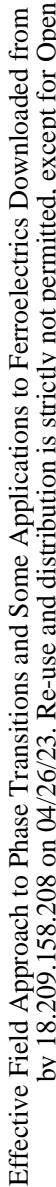




\section{Contents}

Preface vii

Preface to the Second Edition ix

Part 1 Mean Field Approach to Cooperative Phenomena 1

1.1 An overview . . . . . . . . . . . . . . 3

1.2 Liquid-vapor transitions . . . . . . . . . . . . 11

1.3 Ferromagnetic transitions . . . . . . . . . . . . . . . 21

1.4 Superconductive transitions . . . . . . . . . . 31

1.5 Order-disorder transitions in alloys . . . . . . . . 37

1.6 Ferroelectric transitions . . . . . . . . . . . . . . 45

1.7 Superfluid transitions . . . . . . . . . . . . . 53

1.8 Ferroelastic transitions . . . . . . . . . . . . . 61

1.9 Landau theory and effective field approach. Role of

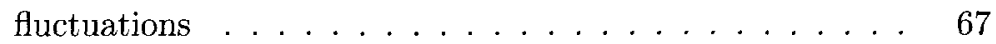

1.10 Equation of state and the scaling function $\ldots \ldots \ldots 8$

Appendix: Effective field approach to superconductors . . . . . . 91

Part 2 Some Applications to Ferroelectrics: 1970-1991 101

2.1 Behavior at $T \cong T_{\mathrm{c}}$ of pure ferroelectric systems with second order phase transition . . . . . . . . . 103

2.2 Effects of dipolar impurities in small amounts . . . . . . 119

2.3 Mixed ferro-antiferroelectric systems and other mixed ferroelectric systems . . . . . . . . . . . . . . . . 129

2.3.1 Comment on "Ferroelectricity in zinc cadmium telluride" . . . . . . . . . . . . . . . . 137 
2.4 Relaxation phenomena near $T_{\mathrm{c}} \ldots \ldots \ldots \ldots \ldots 141$

2.5 Polarization reversal in ferroelectric systems . . . . . . 147

2.6 Polarization switching by domain wall motion . . . . . 155

2.7 Switching current pulse shape . . . . . . . . . . . 163

2.8 Elementary excitations in ferroelectrics: Dipole waves . . . 169

2.9 Low-temperature behavior of ferroelectrics . . . . . . . 179

2.10 Logarithmic corrections . . . . . . . . . . . . . . 183

\section{Part 3 Some Applications to Ferroelectrics: 1991-1997 189}

3.1 Pressure dependence of the free energy expansion coefficients in $\mathrm{PbTiO}_{3}$ and $\mathrm{BaTiO}_{3}$, and tricritical point behavior . . . . . . . . . . . . . . . 191

3.2 Ultrasonic study of the ferroelectric phase transition in $\mathrm{RbD}_{2} \mathrm{PO}_{4} \ldots \ldots \ldots \ldots \ldots$. . . . . . . . . . 197

3.3 New technique for investigating ferroelectric phase transitions: The photoacoustic effect . . . . . . . . 207

3.4 Tricritical point behavior and quadrupole interactions in ferroelectrics . . . . . . . . . . . . . 215

3.5 Frequency and temperature dependence of sound velocity in TGS near $T_{\mathrm{c}} \ldots \ldots \ldots \ldots \ldots \ldots \ldots \ldots$

3.6 Dipolar and higher order interactions in ferroelectric TSCC . . . . . . . . . . . . . . . . 229

3.7 Thermal hysteresis and quadrupole interactions in ferroelectric transitions . . . . . . . . . . . . . 237

3.8 Specific heat and quadrupole interactions in uniaxial ferroelectrics . . . . . . . . . . . . . . . . . . 243

3.9 Field-dependent temperature shift of the dielectric losses peak in TGS . . . . . . . . . . . . . . . . . . 249

3.10 Discontinuity and quasitricritical behavior near $T_{\mathrm{c}}$ in ferroelectric triglycine selenate . . . . . . . . . 255

3.11 Scaling equation of state for ferroelectric triglycine selenate at $T \approx T_{\mathrm{c}} \ldots \ldots \ldots \ldots \ldots \ldots \ldots \ldots \ldots \ldots$

3.12 Composition dependence of the ferroelectric-paraelectric transition in the mixed system $\mathrm{PbZr}_{1-x} \mathrm{Ti}_{x} \mathrm{O}_{3} \ldots \ldots 273$

3.13 Observations of two ferroelectric response times in TGSe at $T \leq T_{\mathrm{c}} \ldots \ldots \ldots \ldots \ldots \ldots \ldots \ldots$

3.14 Equation of state for pressure and temperature induced transition in ferroelectric telluric acid ammonium phosphate 
3.15 Neutron diffraction investigation of the $F_{\mathrm{RL}}-F_{\mathrm{RH}}$ transition in Nb-doped $\mathrm{PbZr}_{1-x} \mathrm{Ti}_{x} \mathrm{O}_{3}$ with $x=0.035 \ldots 2 . \ldots 29$

$3.16 \mathrm{O}_{3}$ tilt and $\mathrm{Pb} /(\mathrm{Zr} / \mathrm{Ti})$ displacement order parameters in $\mathrm{Zr}$-rich $\mathrm{PbZr}_{1-x} \mathrm{Ti}_{x} \mathrm{O}_{3}$ from 20 to $500 \mathrm{~K} \ldots \ldots . . .305$

3.17 Dielectric characterization of the phase transitions in $\mathrm{Pb}_{1-y / 2}\left(\mathrm{Zr}_{1-x} \mathrm{Ti}_{x}\right)_{1-y} \mathrm{Nb}_{y} \mathrm{O}_{3}(0.03 \leq x \leq 0.04,0.025 \leq$ $y \leq 0.05) \ldots \ldots \ldots \ldots \ldots \ldots \ldots \ldots$

\section{Part 4 Some Applications to Ferrolectrics: 1998-2005}

4.1 Scaling and metastable behavior in uniaxial ferroelectrics . . . . . . . . . . . . . . . 337

4.2 Energy conversion with Zr-rich lead Zirconate/Titanate ceramics . . . . . . . . . . . . . . . 351

4.3 Microscopic characterization of low-field switching in ferroelectric TGS . . . . . . . . . . . . . . . 357

4.4 Brillouin scattering studies of ferroelectric triglycine selenate sound velocity versus uniaxial pressure at $T \sim T_{C} \ldots \ldots \ldots \ldots \ldots \ldots \ldots \ldots$

4.5 Piezoelectric resonance investigation of Zr-rich PZT at room temperature . . . . . . . . . . . . 377

4.6 Transition temperature dependence in perovskite ceramics as a function of grain size . . . . . . . . . . 385

4.7 A monoclinic ferroelectric phase in the $\mathrm{Pb}\left(\mathrm{Zr}_{1-x} \mathrm{Ti}_{x}\right) \mathrm{O}_{3}$ solid solution . . . . . . . . . . . . . . . 389

4.8 Tetragonal-to-monoclinic phase transition in ferroelectric perovskite: The structure of $\mathrm{PbZr}_{0.52} \mathrm{Ti}_{0.48} \mathrm{O}_{3} \ldots \ldots .397$

4.9 Evolution of the ferroelectric transition character of partially deuterated triglycine selenate . . . . . . . . 419

4.10 Composition dependence of transition temperature in mixed ferroelectric-ferroelectric systems . . . . . . . . 427

4.11 Temperature dependence of mode Grüneisen parameters in ferroelectric perovskites at $T \cong T_{\mathrm{c}} \ldots \ldots \ldots . \ldots 435$

4.12 Quantum tunneling versus zero point energy in double-well potential model for ferroelectric phse transitions . . . . . . 439 